\title{
Sacroiliac joint involvement in spinal tuberculosis
}

\author{
Khan $\mathrm{F}^{1}$, Govender $\mathrm{S}^{2}$ \\ 1 MBChB(UKZN), FC(Orth)SA; Orthopaedic Consultant/Fellow; Department of Orthopaedic Surgery, School of Clinical Medicine, College of Health Sciences, \\ University of KwaZulu-Natal, Durban \\ 2 MBBS, MD, FRCS, FC(Orth)PR; Professor and orthopaedic surgeon, Spinal Unit, King Dinizulu Hospital, Durban; Fellow of University of KwaZulu-Natal, Durban
}

Corresponding author: Dr F Khan, cell: 0726947947; email: faraazk786@gmail.com

\begin{abstract}
Background: A discussion of the incidence and pathogenesis of tuberculosis of the sacroiliac joint and a description of an association with spinal tuberculosis.

Methods: A retrospective chart review was conducted in the spine unit on all inpatients admitted between 1 July 2014 and 30 June 2015. Patients with confirmed tuberculous spondylitis and/or sacroiliitis, who underwent adequate radiological examination of their sacroiliac joints, were included in the study. Available clinical and radiological investigations including plain X-rays, CT and MRI scans, were scrutinised to actively exclude sacroiliac joint involvement.

Results: Sixty-six patients with tuberculous spondylitis and one patient with isolated tuberculous sacroiliitis were included in the study. Seventeen patients had multilevel (>2 levels) contiguous involvement, while 14 patients had multilevel non-contiguous lesions. Thirty-four patients had associated iliopsoas abscesses. Thirteen patients (19.4\%) were identified as having involvement of their sacroiliac joint(s). Six had bilateral involvement, five with right-sided and two patients with left-sided involvement. Eleven of the patients identified had associated iliopsoas abscesses, two of whom had gluteal and iliopsoas abscesses. The patient with isolated sacroiliac joint involvement had a gluteal abscess.
\end{abstract}

Conclusion: Concurrent radiographic evidence of sacroiliac joint involvement is not uncommon in patients with spinal tuberculosis, more so when abscess formation is associated, and should be actively looked for and excluded in such cases.

Level of evidence: Level 4

Key words: tuberculous, sacroiliac, tuberculosis, spondylitis, sacroiliitis

Citation: Khan F. Sacroiliac joint involvement in spinal tuberculosis. SA Orthop J 2018;17(3):47-52. http://dx.doi.org/10.17159/2309-8309/2018/v17n3a6 Editor: Prof LC Marais, University of KwaZulu-Natal, Durban

Received: May 2017

Accepted: December 2017

Published: August 2018

Copyright: (C) 2018 Khan F. This is an open-access article distributed under the terms of the Creative Commons Attribution Licence, which permits unrestricted use, distribution and reproduction in any medium, provided the original author and source are credited.

Funding: No benefits in any form have been received or will be received from any commercial party related directly or indirectly to the subject of this article.

Conflict of interest: The authors have no conflicts of interest to declare with respect to this article. 


\section{Introduction}

Tuberculous involvement of the sacroiliac joint is reported as rare in the literature and is estimated to account for 0.3 to $0.5 \%$ of all tuberculosis cases. ${ }^{1-4}$ While this may be true in the developed world or when looked at in isolation, the incidence is much higher in less developed countries, ${ }^{5,6}$ with ever-increasing rates of retroviral disease (RVD) associated with atypical pathology and multifocal skeletal involvement. Involvement may be further underestimated due to a recognised vague presentation, $, 1,2,4,5,7-10$ and the sacroiliac joint being a region that is easily overlooked during routine clinical and radiological examinations. ${ }^{1,4-9}$

Numerous studies have noted an association of tuberculous sacroiliitis with concurrent spinal tuberculosis.1,2,5,11,12 An association with paraspinal and/or gluteal abscesses has also

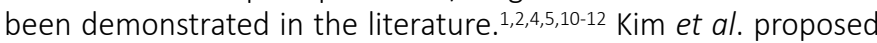
a four-stage classification as a guide to the management approach (Table I), differentiating cases that may benefit from surgery, from those that could be managed conservatively with chemotherapy alone. $^{2}$

The aim of this study was to discuss the incidence and pathogenesis of tuberculosis involvement of the sacroiliac joint and describe an association with spinal tuberculosis and abscess formation.

Table I: Classification of sacroiliac joint tuberculosis proposed by Kim et al. ${ }^{4}$ Types were defined according to the severity of clinical and radiographic findings.

\begin{tabular}{|l|l|}
\hline Type & \multicolumn{1}{c|}{ Description } \\
\hline I & $\begin{array}{l}\text { Widening of the joint space and blurring on the margin of } \\
\text { the sacroiliac joint }\end{array}$ \\
\hline II & Erosion of the sacroiliac joint \\
\hline III & $\begin{array}{l}\text { Severe destruction of the sacroiliac joint with cyst } \\
\text { formation of the ilium and sacrum, and marginal sclerosis }\end{array}$ \\
\hline IV & $\begin{array}{l}\text { A lesion of the sacroiliac joint with abscess formation or } \\
\text { other affected vertebra }\end{array}$ \\
\hline
\end{tabular}

\section{Materials and methods}

A retrospective chart review was conducted in the spine unit on all inpatients admitted between 1 July 2014 and 30 June 2015. Patients with confirmed tuberculous spondylitis and/or sacroiliitis, who underwent adequate radiological examination of their sacroiliac joints, were included in the study. Available clinical and radiological investigations including plain X-rays, computed tomography (CT) and magnetic resonance imaging (MRI) scans, were scrutinised for sacroiliac joint involvement.

Patients with spondylitis and/or sacroiliitis arising from pathogens other than

mycobacterium tuberculosis, outpatients, and those with confirmed tuberculous spondylitis without adequate radiological visualisation of their sacroiliac joints were excluded from the study.

\section{Results}

Ninety-one patients with spinal tuberculosis and one patient with isolated tuberculous sacroiliitis were admitted over the 12-month period. Histological confirmation of tuberculosis was attained in 71 patients revealing chronic granulomatous inflammatory tissue with patchy infiltration of acid-fast bacilli, giant and epithelioid cells, varied degrees of caseous necrosis and tubercle formation. Among these, 16 patients had positive cultures for Mycobacterium tuberculosis on Lowenstein Jensen medium. In the remaining

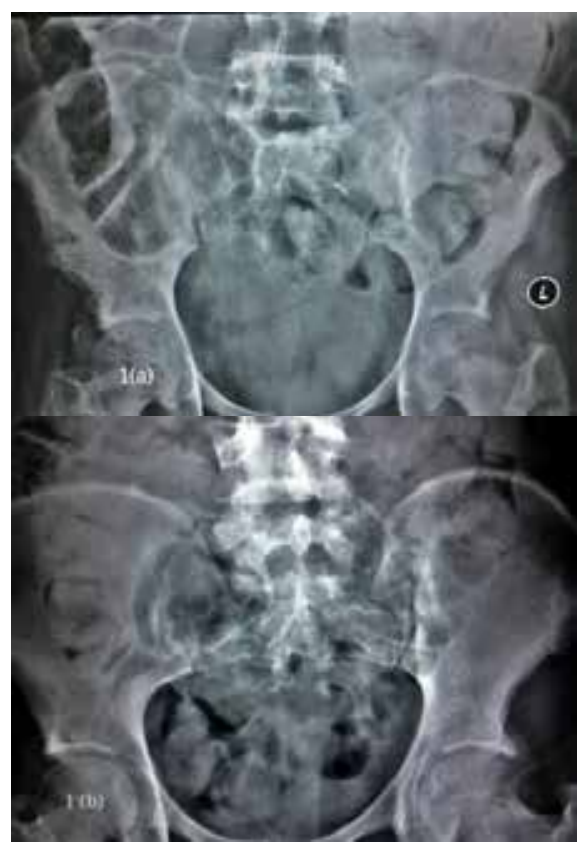

Figure 1(a) and (b).

Plain X-rays

demonstrating

inadequate

visualisation of the sacroiliac joints due to overlying bowel shadows

patients, diagnosis was based on clinical, haematological and radiological findings.

Twenty-five patients were excluded from the study due to inadequate radiological visualisation of their sacroiliac joints. These included six patients with cervical spine and 16 patients with upper-to-mid thoracic spine involvement with incomplete inclusion of their sacroiliac joints on CT and/or MRI studies. Although plain X-rays were performed in all patients, adequate and complete visualisation of both sacroiliac joints was not possible due to overlying bowel shadows (Figure 1).

The 67 patients in our study group included 37 females and 30 males with ages ranging from 2 to 74 years. The thoracic and lumbar regions were affected in the majority of patients with seven patients having involvement at or below the lumbosacral junction and three patients with cervical spine involvement. Seventeen patients had multilevel ( $>2$ levels) contiguous spinal involvement and 14 patients had multilevel non-contiguous involvement. Thirtyfour patients had associated abscess formation. All patients were investigated with plain X-rays and $\mathrm{CT}$, while MRI was performed in 29 patients.

Thirty-two patients had multifocal disease having either active pulmonary and/or extrapulmonary involvement, or previous history of tuberculosis. Forty-two patients had clinical evidence of partial or complete neurological deficit. Twenty-one patients had documented tenderness of their sacroiliac joint(s); however, the lateral pelvic compression, Gaenslen and FABER tests were performed in only 16 patients for obvious reasons. Forty-six patients had confirmed RVD and a further 14 patients had an unknown retroviral status. Erythrocyte sedimentation rates ranged from 8 to $>140 \mathrm{~mm} / \mathrm{hr}$. Five patients were diagnosed with multidrug resistant (MDR) tuberculosis.

Thirteen patients (19.4\%) were identified as having involvement of their sacroiliac joint(s), including the patient with isolated sacroiliitis (Table II). There were eight females and five males whose ages ranged from 13 to 64 years. Eight patients had lower back and/or buttock pain without neurological deficits, three patients had partial neurological deficit with lower limb weakness, and two patients had spastic paraplegia. Of the 12 patients with spondylitis, eight were atypical with multilevel contiguous or non-contiguous lesions. One patient had skip lesions involving all regions of the spine (Figure 2 ) and 11 patients had involvement of the lumbar region. One of the 13 patients identified was HIV negative and one patient had an unknown retroviral status. 


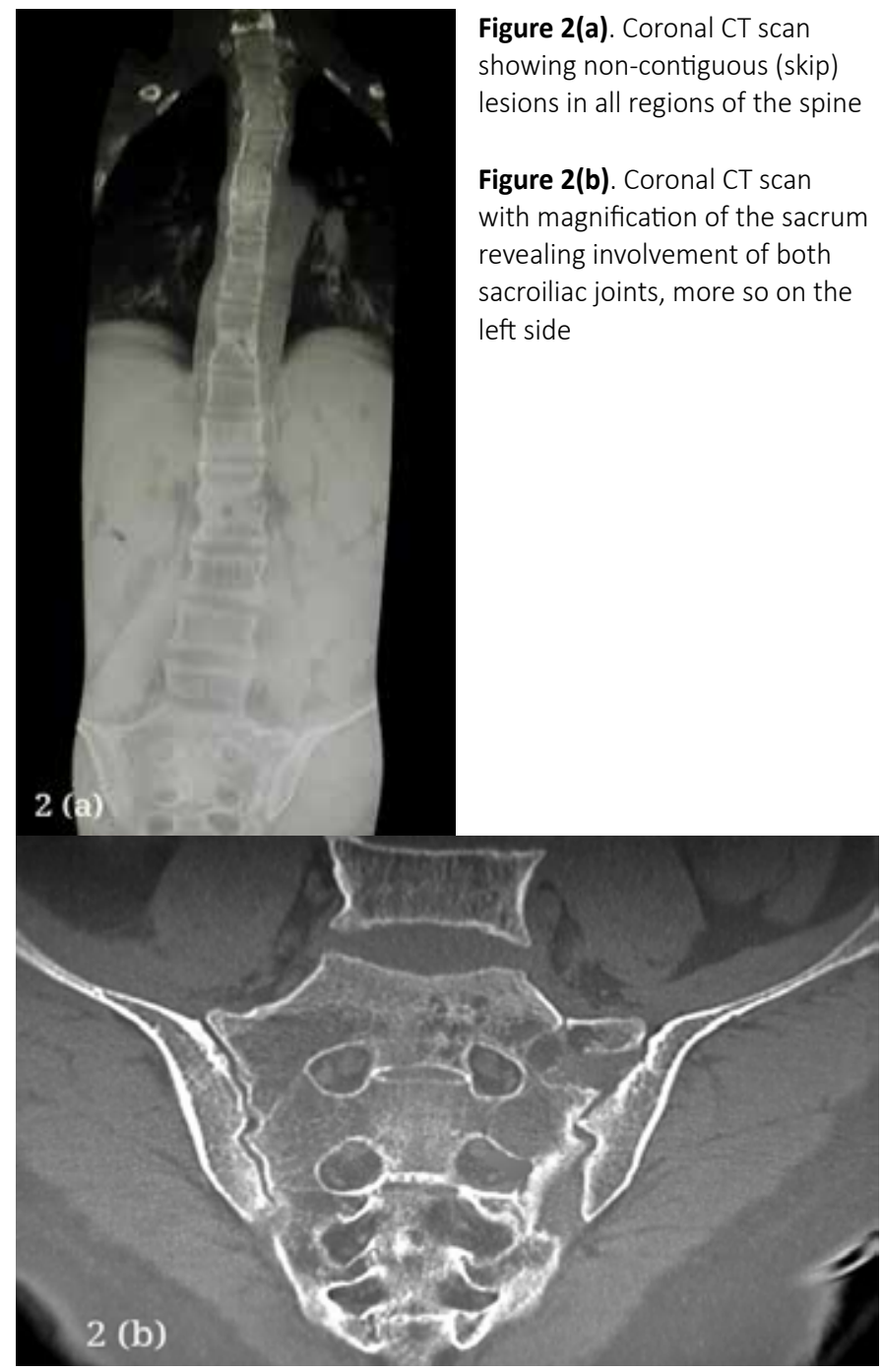

Radiological bony changes varied from erosions, cyst formation and sclerotic margins (Figure 3), to marked joint destruction and sequestration (Figure 4). Questionable joint space widening or blurred margins were regarded as being uninvolved. Destructive lesions were predominantly seen in the antero-inferior aspects; however, inconsistent distributions were seen in three joints. Bony changes were best seen on CT with several patients having inadequate plain X-rays. MRI was performed in five patients with associated neurological deficit.

Eight of the 13 patients had open biopsies of their sacroiliac joints. In three patients, including two patients with early sacroiliac joint changes, biopsies of the spinal lesions were performed. In the remaining two patients, the diagnosis was based on classic radiological vertebral changes demonstrating two body disease suggestive of tuberculosis as well as grade 2 sacroiliac joint changes.

Histopathology confirmed chronic granulomatous inflammatory tissue, varied degrees of caseous necrosis and tubercle formation with/without giant and epitheloid cells. Microscopy did not reveal the presence of any other pathogens and acid-fast bacilli were demonstrated in two cases. Polymerase chain reaction was not available for use at the time and no record of such results were found.

Six patients had bilateral sacroiliac joint involvement, five with right-sided and two patients with left-sided involvement. Twelve of the 13 patients had associated abscess formation. Eleven patients had iliopsoas abscesses, two of whom had both gluteal and iliopsoas abscesses. The patient with isolated sacroiliac joint involvement had a gluteal abscess. Three patients presented with draining sinuses, one of whom demonstrated MDR disease.

According to the Kim classification (Table I), all 13 patients had type IV disease. Eleven patients underwent surgical interventions ranging from debridement and drainage of abscesses to spinal decompression and stabilisation. Eight patients underwent open biopsies of their sacroiliac joints and six patients required sacroiliac joint debridement with/without arthrodesis. Negative pressure

Table II: Data sheet of the 13 patients with sacroiliac joint involvement. Twelve patients had associated vertebral involvement and one patient had isolated sacroiliitis.

\begin{tabular}{|c|c|c|c|c|c|c|c|}
\hline \multirow{2}{*}{$\begin{array}{l}\text { Age } \\
\text { Sex }\end{array}$} & \multirow[t]{2}{*}{ RVD status } & \multirow{2}{*}{$\begin{array}{c}\text { Abscess } \\
\text { formation }\end{array}$} & \multirow{2}{*}{$\begin{array}{l}\text { Spinal level(s) } \\
\text { involved }\end{array}$} & \multicolumn{4}{|c|}{ Sacroiliac joint evaluation } \\
\hline & & & & Clinical & X-ray & CT scan & MRI scan \\
\hline $13 \mathrm{M}$ & Positive & Psoas & T10-12; L2-S2 & Non-tender; sensory deficit & Inadequate & Adequate & Adequate \\
\hline $19 \mathrm{~F}$ & Unknown & Psoas + gluteal & L5, S1 & Tenderness & Adequate & Adequate & - \\
\hline $28 \mathrm{~F}$ & Positive & Psoas & $\mathrm{T} 10,11$ & $\begin{array}{c}\text { Non-tender; spastic } \\
\text { paraplegia }\end{array}$ & Inadequate & Adequate & Adequate \\
\hline $28 \mathrm{M}$ & Positive & Psoas & $\begin{array}{l}\text { C3, } 4 ; \mathrm{T} 9,10 \\
\mathrm{~L} 1,2\end{array}$ & Tenderness; sinus & Inadequate & Adequate & - \\
\hline $32 \mathrm{~F}$ & Positive & Psoas & $\begin{array}{c}\mathrm{T} 1-3,5,6,11 \\
12 ; \mathrm{L} 3,4\end{array}$ & $\begin{array}{c}\text { Non-tender; spastic } \\
\text { paraplegia }\end{array}$ & Inadequate & Adequate & Adequate \\
\hline $33 \mathrm{M}$ & Positive & Psoas & L3-S2 & Tenderness & Adequate & Adequate & - \\
\hline $36 \mathrm{M}$ & Positive & Psoas & $\mathrm{T} 11-\mathrm{L} 3$ & Tenderness & Inadequate & Adequate & - \\
\hline $37 \mathrm{~F}$ & Positive & Psoas & $\mathrm{L} 1-3$ & Tenderness & Inadequate & Adequate & - \\
\hline $44 \mathrm{M}$ & Positive & Psoas + gluteal & $L 2,3$ & $\begin{array}{c}\text { Non-tender; sinus; sensory } \\
\text { deficit }\end{array}$ & Inadequate & Adequate & Adequate \\
\hline $44 \mathrm{~F}$ & Positive & Gluteal & - & Tenderness & Inadequate & Adequate & - \\
\hline $46 \mathrm{~F}$ & Positive & - & L5, S1 & Tenderness & Adequate & Adequate & - \\
\hline $49 F$ & Positive & Psoas & L1-S1 & Tenderness; sinus & Inadequate & Adequate & - \\
\hline $64 \mathrm{~F}$ & Negative & Psoas & $\mathrm{L} 2,3$ & Non-tender; sensory deficit & Inadequate & Adequate & Adequate \\
\hline
\end{tabular}




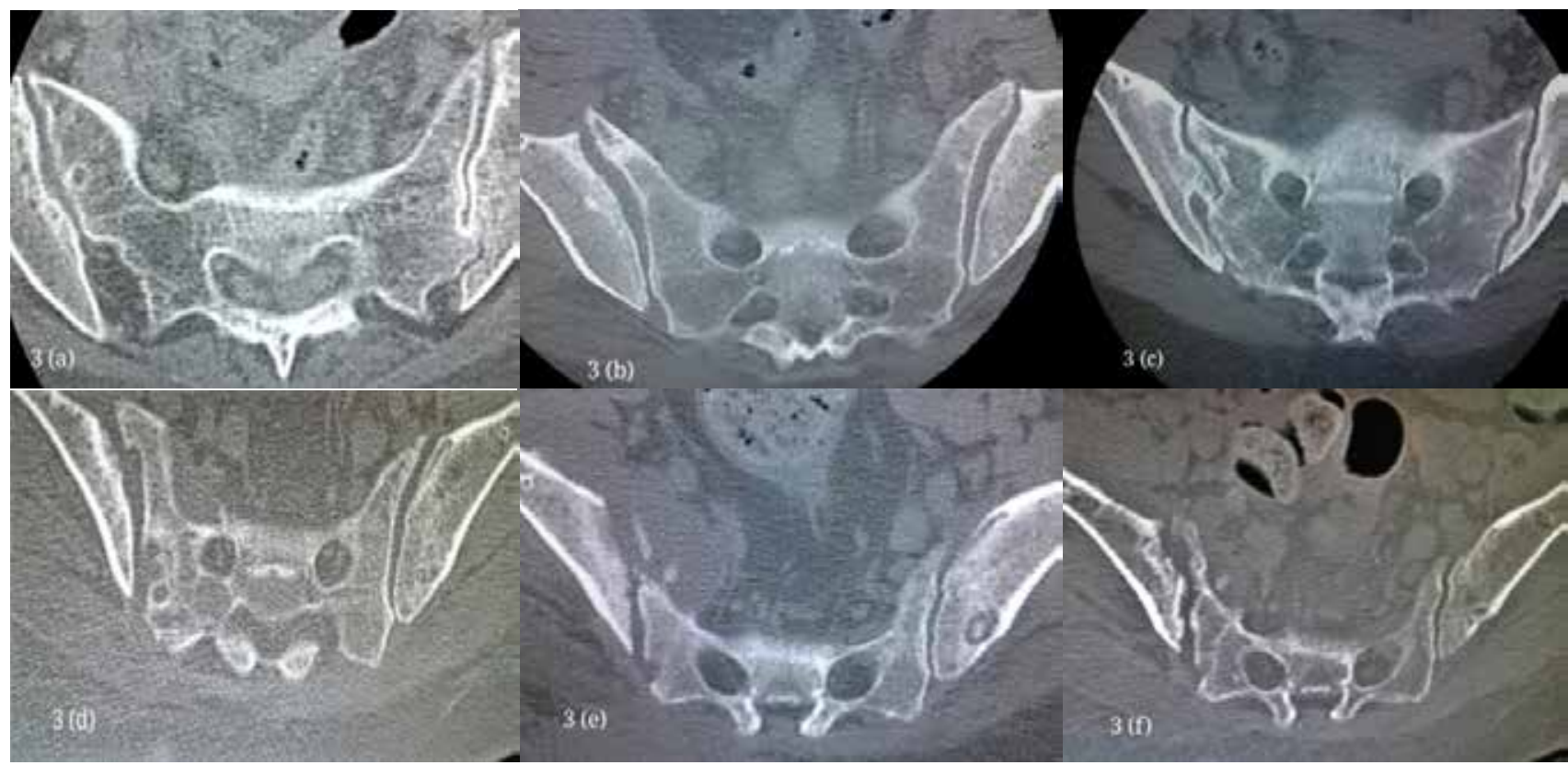

Figure $\mathbf{3}(\mathbf{a})-\mathbf{( f )}$. Axial CT scans showing six cases with varying degrees of sacroiliac joint involvement including joint space widening, erosions, cysts and marginal sclerosis

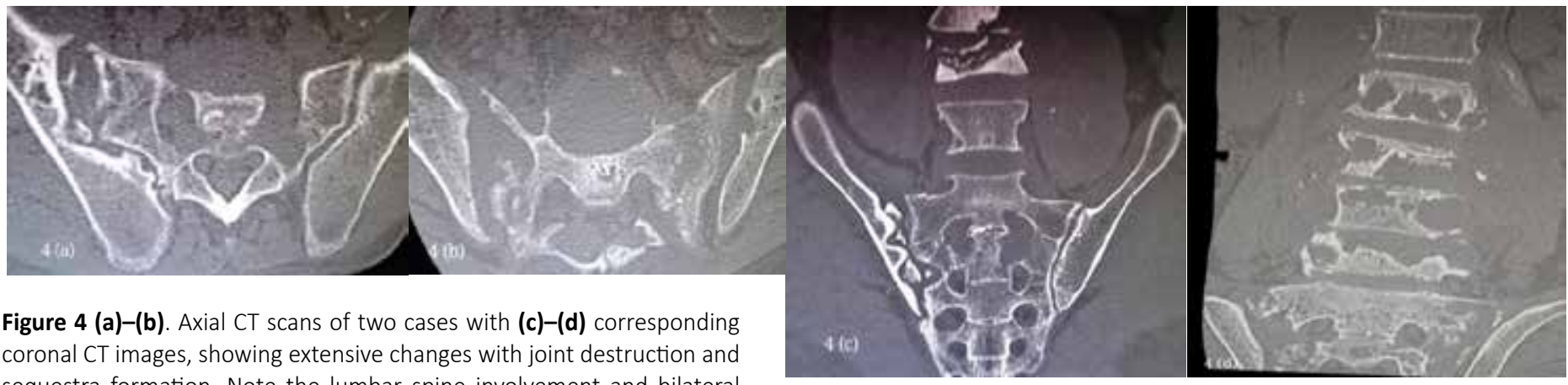
sequestra formation. Note the lumbar spine involvement and bilateral iliopsoas abscesses in both cases.

wound therapy was used in all patients with sinuses. Outpatient follow-up and treatment outcomes however, are beyond the scope of this study.

Two patients had no documented involvement of their sacroiliac joints and were treated primarily for their spinal lesions. However, both patients had early radiographic joint changes not requiring surgical intervention, and were treated adequately with antituberculous chemotherapy.

\section{Discussion}

The relative paucity of available literature on tuberculosis of the sacroiliac joint has been largely attributed to its rarity. ${ }^{1-4,10,12} \mathrm{~A}$ large proportion of the published literature from the developed world is limited to sporadic case reports ${ }^{4,5,8,10,12,13}$ with studies of significance conducted over several years. ${ }^{1,2,11}$ In a landmark study, ${ }^{2}$ 16 cases were identified over a period spanning two decades. However, a more recent study ${ }^{6}$ in an endemic area identified 35 cases over a 4-year period. The substantial discrepancy is a result of significantly lower rates of underlying immune-suppressive conditions like RVD, low socio-economic status, malnutrition, etc., in the developed world.

The rates of both RVD and tuberculosis in South Africa, are among the highest in the world. ${ }^{14,15}$ Improved awareness and availability of antiretroviral therapy has transformed the expression of
RVD from a rapidly progressive affliction with a high mortality rate, to one that presents more like a chronic medical condition with improving survival rates. ${ }^{16}$ Tuberculosis, on the other hand, has become more difficult to treat over recent years with everincreasing rates and the emergence of drug-resistant strains. The combined effect of these factors contributes to the increasing number of patients with atypical pathology and multifocal disease. Almost half of the 67 patients in our study group and eight of the 13 patients with sacroiliac joint involvement, presented with atypical pathology.

Numerous studies ${ }^{1,2,4,10-12,17-19}$ have demonstrated an association of tuberculous sacroiliitis with spinal TB and abscess formation, to the extent of inclusion as a subtype (type IV), in the proposed classification. This is the first study to look at identifying sacroiliac joint involvement in this particular subgroup of patients, highlighting several factors requiring consideration.

Mycobacterium tuberculosis may reach the sacroiliac joints via haematogenous or lymphatic routes from other primary sites of infection. The most common sites are the pulmonary system or spine, with the spine well recognised as the commonest skeletal site. It may spread contiguously through surrounding soft tissues or less commonly, mycobacteria may lodge as latent foci during the primary infection and activate at a later stage.

Therefore, in a patient with vertebral involvement and iliopsoas abscesses, spread to the sacroiliac joints may occur via all possible 
routes, and a higher risk of transmission would be expected. This is further supported by our findings, with almost a fifth (19.4\%) of the patients having sacroiliac involvement, and 12 of these 13 patients having abscess formation. On the other hand, in a patient with isolated tuberculous sacroiliitis without other active sites of involvement, the infection originates from activation of latent foci which occurs less frequently, especially in developed countries.

Tuberculous sacroiliitis may present in various clinical settings. Isolated sacroiliac joint involvement often presents as a patient with refractory, poorly localised lower back or buttock pain with/without constitutional symptoms. Patients are usually neurologically intact or at worst have evidence of radiculopathy. In patients with vertebral involvement however, a wide spectrum of presentations may occur, ranging from mild backache to obvious spinal deformity with complete neurological deficit.

While sacroiliac joint pathology is well renowned for being elusive to clinical detection and prone to late diagnosis even when it occurs in isolation, 5,6,8-10,13 concurrent vertebral involvement adds a host of challenges to the clinical and radiological evaluation.

Patients often present with symptoms from their spine pathology including pain, deformity and neurological compromise. A patient with a high level sensory deficit, may not complain of sacroiliac joint pain and the clinical focus is on performing a spinal and neurological assessment. Furthermore, provocative testing of the sacroiliac joints would be extremely difficult and is often excluded in patients with spinal instability, to near impossible in patients with complete neurological lesions.

The radiological evaluation of the sacroiliac joints in these patients must also be considered. The higher the level of the spinal lesions, the less likely that the sacroiliac joints would be included in imaging studies. This was evident in our findings as 22 of the 25 exclusions were patients with vertebral lesions above the mid-thoracic spine. These patients are incidentally more likely to have significant neurological deficits, are often immobile and have associated bladder or bowel involvement. The accompanying faecal loading often obscures complete visualisation of their sacroiliac joints on plain X-rays. If plain radiography is the only available imaging modality, prior bowel preparation and the use of oblique views ${ }^{6}$ is advised.

Depending on the route of transmission to the sacroiliac joint, infection may originate in the sacral or ileal sides, or from the synovium. The resultant inflammatory exudate and bone oedema radiographically appears as haziness or blurring of the joint margins and widening of the joint space, which are the earliest identifiable changes described. Further disease progression causes subchondral erosions with formation of periarticular cysts in the sacrum and/or ilium. If untreated, marginal sclerosis occurs with eventual joint destruction and sequestra formation. Concurrent periarticular soft tissue involvement manifests as abscesses, through various tissue planes and directions, with eventual sinus formation.

While MRI has been shown to be useful in the detection of early disease, ${ }^{6,12}$ it is less freely available and affordable in the developing world where delayed presentation is common. As a result, MRI is not routinely performed in all patients with vertebral pathology but usually reserved for those with associated neurological deficit. Furthermore, while soft tissue pathology is best seen on MRI, subtle bony changes are less clearly defined (Figure 5). Computed tomography has been shown to demonstrate the best definition and extent of bony pathology, ${ }^{1,2,10,19}$ as appreciated in this series, identifying sacroiliac joint involvement in all cases.

Regardless of the extent of sacroiliac joint changes, all 13 cases identified had type IV disease, as 12 patients had other affected vertebra and the patient with isolated sacroiliitis had a

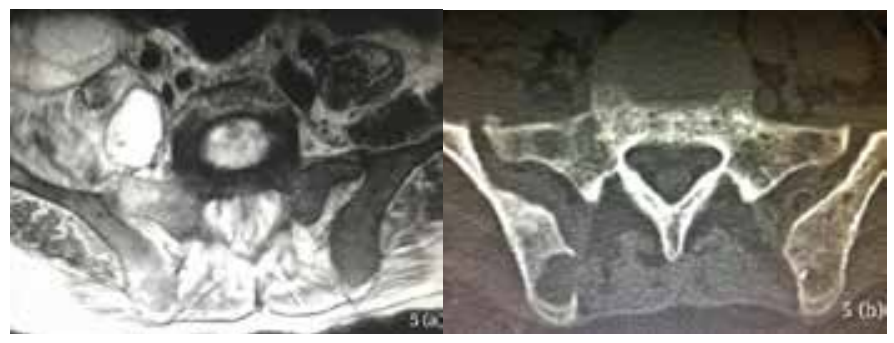

Figure 5. (a) Axial T2-weighted MRI scan showing improved soft tissue enhancement and, (b) the axial CT scan demonstrating defined bony changes

gluteal abscess. A closer look at the classification (Table I) reveals that types I to III are based on the severity of radiographic bony changes, ranging from a blurred and widened joint space in type I, to cyst formation, marginal sclerosis and joint destruction in type III disease. Type IV however, was defined as, 'a lesion of the sacroiliac joint with abscess formation or other affected vertebra'. ${ }^{2}$

Patients with type IV disease may thus have variable degrees of sacroiliac joint changes, as illustrated in our findings. Furthermore, spinal tuberculosis with or without abscess formation may occur prior to sacroiliac joint involvement, as seen in this study, where several patients demonstrated advanced vertebral involvement with iliopsoas abscesses and only early radiographic changes in their sacroiliac joints. For these reasons, we recommend that the classification be modified to three types, and to include vertebral involvement or abscess formation as a subclass of all types (Table III). This modification may assist in formulating more accurate guidelines to the management plan.

Table III: Modification of the classification to three types with abscess formation and/or other affected vertebra added as a subclass to all types

\begin{tabular}{|l|l|l|}
\hline Type & \multicolumn{2}{|c|}{ Subtypes with description } \\
\hline I & $\begin{array}{l}\text { IA - Widening of the joint } \\
\text { space and blurring on the } \\
\text { margin of the sacroiliac joint }\end{array}$ & $\begin{array}{l}\text { IB }- \text { IA with abscess } \\
\text { formation and/or other } \\
\text { affected vertebra }\end{array}$ \\
\hline II & $\begin{array}{l}\text { IIA - Erosion of the sacroiliac } \\
\text { joint }\end{array}$ & $\begin{array}{l}\text { IIB }- \text { IIA with abscess } \\
\text { formation and/or other } \\
\text { affected vertebra }\end{array}$ \\
\hline III & $\begin{array}{l}\text { IIIA - Severe destruction } \\
\text { of the sacroiliac joint with } \\
\text { cyst formation of the ilium } \\
\text { and sacrum and marginal } \\
\text { sclerosis }\end{array}$ & $\begin{array}{l}\text { IIIB - IIIA with abscess } \\
\text { formation and/or other } \\
\text { affected vertebra }\end{array}$ \\
\hline
\end{tabular}

Thus, concurrent vertebral involvement exposes numerous additional challenges to a condition known to have a difficult and often late diagnosis. Furthermore, the mainstay in the treatment of tuberculous sacroiliitis is conservative and most symptomatic patients will resolve completely on chemotherapy alone. Consequently, a significant number of patients in this subset of patients may be easily overlooked, thereby further underestimating the overall incidence.

A major drawback of this study is that only a particular subgroup of patients was used, in whom the incidence of tuberculous sacroiliitis would be expected to be higher. Our results therefore only reflect the incidence among this particular subgroup of patients and not that of the general population. Another drawback was that the diagnosis of tuberculous sacroiliitis was not confirmed with complete certainty in all cases. Other pathogens or aetiologies, although less likely, were still possible, and as outpatient follow-up was not included, treatment responses could 
not be assessed or discussed. We therefore recommend that more prospective studies be conducted among this subgroup of patients.

\section{Conclusion}

Concurrent radiographic evidence of sacroiliac joint involvement is not uncommon in patients with spinal tuberculosis, more so when abscess formation is associated, and should be actively looked for and excluded in such cases. Computed tomography is the recommended imaging modality in the evaluation and diagnosis of tuberculous sacroiliitis.

\section{Ethics statement}

This study received full ethics approval by the Biomedical Research Ethics Committee of the University of KwaZulu-Natal.

\section{References}

1. Ramlakan RJS, Govender S. Sacroiliac joint tuberculosis Int. Orth 2007; 31(1):121-24

2. Kim NH, Lee HM, Yoo JD, Suh JS. Sacroiliac joint tuberculosis - Classification and treatment Clin Orth Rel Research 1999;358:215-22.

3. Daies PDO, Humphries MJ, Byfield SP, et al. Bone and joint tuberculosis. A survey of notifications in England and Wales. $J$ Bone joint Surg, 1984; 66B:326-30.

4. Garg I.K, Kumar L, Gaurav J, Case report. Tuberculosis of sacroiliac joint - A rare case. J, Advance Researches in Biological Sciences 2012;4(1):85-87.

5. Gupta R, Beimenstoch H, Morano P, Gupta A. Tuberculosis of sacroiliac joint - An unusual presentation. I Natl Med Assoc 2005;97(8):1174-76.

6. J Prakash. Sacroiliac tuberculosis - A neglected differential in refractory low back pain J Clin Orthop Trauma. 2014 Sep;5(3):146-53.

7. Pouchot J, Vinceneux P, Borge J, Boussougeut $Y$, Pierre J, Carbon C, Kahn MF. Tuberculosis of the sacroiliac joint - clinical features, outcome and evaluation of closed needle biopsy, Am Journal of Medicine 1988;84(3 Pt 2):622-28.

8. Chen WS. Chronic sciatica caused by tuberculosis sacroiliitis - a case report. Spine 1995;20:1194-96.

9. Laeslett $M$, Williams $M$. The reliability of selected pain provocation tests for sacroiliac joint pathology. Spine 1994;19:1243-48.

10. Papagelopoulos PJ, Padapoulos EC, Mavrogenis AF Themistocleous GS, Korres DS, Soucacos PN. Tuberculous sacroiliitis. A case report and review of the literature. Eur Spine J 2005;14(3):683-88.

11. Soholt ST. Tuberculosis of the sacro-iliac joint Am JBJS 1951;33A:119-30.

12. Gelal F, Sabah D, Dogan R, Avci A. Multifocal skeletal tuberculosis involving the L-spine and a sacro-iliac joint. Diagn Inter Radiology 2006;12(3):139-41.

13. Nakase M. Tuberculosis of the sacroiliac joint: A case report. Japanese Journal of Joint Diseases 2009;28(2):261-64.

14. Dye C, Floyd K, Uplekar M. WHO report 2008. Global tuberculosis control: surveillance, planning, financing. World Health Organization, Geneva, Switzerland

15. WHO report 2011. Global tuberculosis control: surveillance, planning, financing. World Health Organization, Geneva, Switzerland

16. Herbst AJ, Cooke GS, Barnghausen T, KanyKany A, Tanser F, Newell ML. Adult mortality and antiretroviral roll-out in rural KwaZulu-Natal, South Africa. Bull WHO 2009;87(10):754-62.
17. Richter R, Nubling W, Kobler G, Ilinski A. Tuberculosis of the iliosacral joint. Treatment, results prognosis and differential diagnosis. Z orthop Ihre Grenzeb 1983;121:564-70.

18. Benchakroun M, El Badouni A, Zaddoug O. Tuberculous sacroiliitis: four cases. Joint Bone Spine 2004;71:150-53.

19. Osman AA, Govender S. Septic sacroiliitis. Clin Orthop 1995;313:214-19. 